\title{
Article
}

\section{The Longitudinal Israeli Study of Twins (LIST) Reaches Adolescence: Genetic and Environmental Pathways to Social, Personality and Moral Development}

\author{
Dana Vertsberger, Lior Abramson and Ariel Knafo-Noam \\ Department of Psychology, Hebrew University of Jerusalem, Jerusalem, Israel
}

\begin{abstract}
The Longitudinal Israeli Study of Twins (LIST) focuses on the developmental, genetic and environmental contributions to individual differences in children's and adolescents' social behavior. Key variables have been empathy, prosocial behavior, temperament and values. Another major goal of LIST has been to study gene-environment correlations, mainly concerning parenting. LIST includes 1657 families of Hebrew-speaking Israeli twins who have participated at least once in the study. Children's environment and their development are assessed in a multivariate, multimethod fashion, including observed, parent-reported and self-reported data. The current article summarizes and updates recent findings from LIST. For example, LIST provided evidence for the heritability of human values with the youngest sample to date, and the first genetic investigation of adolescents' identity formation. Finally, future aims of LIST are discussed.
\end{abstract}

Keywords: behavioral genetics; empathy; gene-environment correlation; LIST; parenting; prosocial behavior; temperament; twin relationships; values

(Received 5 June 2019; accepted 7 July 2019; First Published online 23 October 2019)

Modern developmental research seeks to understand the intricate network of influences of the different environments children grow up in as well as children's characteristics that shape children's and adolescent's development (Davidov et al., 2015; Rutter et al., 2006). One goal of the Longitudinal Israeli Study of Twins (LIST; Avinun \& Knafo, 2013; Knafo, 2006) is to address this complexity by studying the association between genetic factors and the environments children grow up in, which is referred to as gene-environment correlations ( $r$ GE; Knafo \& Jaffee, 2013; Plomin et al., 1977). The other major goal of LIST is to study the origins of individual differences in the positive aspects of morally relevant development. There are over a hundred genetically informative studies on antisocial behavior (e.g. Burt, 2009). In contrast, there are much fewer studies on the genetics of moral variables (Israel et al., 2015). Thus, the majority of LIST work has focused on the genetic, environmental and developmental background of variables such as prosocial behavior, empathy and values.

\section{Data Collection}

LIST includes 1657 families of Hebrew-speaking Israeli twins who have participated at least once in the study. Recruitment commenced in 2007 when the twins were 3 years old. Families of twins from across the country were identified with national information on multiple births provided by the Ministry of the Interior. Twins have

Author for correspondence: Ariel Knafo-Noam, Email: ariel.knafo@huji.ac.il

Cite this article: Vertsberger D, Abramson L, and Knafo-Noam A. (2019) The Longitudinal Israeli Study of Twins (LIST) Reaches Adolescence: Genetic and Environmental Pathways to Social, Personality and Moral Development. Twin Research and Human Genetics 22: 567-571, https://doi.org/10.1017/thg.2019.94 been subsequently followed on a typically biannual rate (see Table 1). At ages 3.5, 5 and 7 years, the subsample of families living in the Jerusalem area participated in an observational session at the lab. Ages 6.5 and 8-9 years involved a larger sample of either home or lab visits that also included families from the center and north of Israel. Observational sessions focused mainly on same-sex twins. Currently, age 15 data are being collected, with plans for followup at age 17 and later on. Past reports on the LIST twin registry provide further details on the sample and recruitment (Avinun \& Knafo, 2013; Knafo, 2006).

At all ages, mothers were asked to describe children's development using questionnaires, which mainly focused on twins' relationships, behavior and temperament as well as demographic details and socioeconomic status. When available, fathers filled similar versions of the questionnaires. Starting from age 11, adolescents and their parents participate in the study through a specialized online portal. Contact with the families has been maintained through regular newsletters, a website and most recently in a special event honoring twins and their families at the Bloomfield Science Museum in Jerusalem.

\section{Zygosity Assignment}

Zygosity was assessed by DNA using 10 genetic markers for $44.6 \%$ of the same-sex twin pairs. Twins' DNA was isolated from buccal epithelial cells using buccal swab brushes that were kept after collection in a sterile tube containing $15 \mathrm{ml}$ of Aquafresh mouthwash. Parents' DNA was extracted from $20 \mathrm{ml}$ of Aquafresh mouthwash samples. DNA was extracted using the Master Pure kit (Epicentre, Madison, WI). When DNA was not available, zygosity was 
Table 1. LIST MZ and DZ pairs and data collected according to age and data type

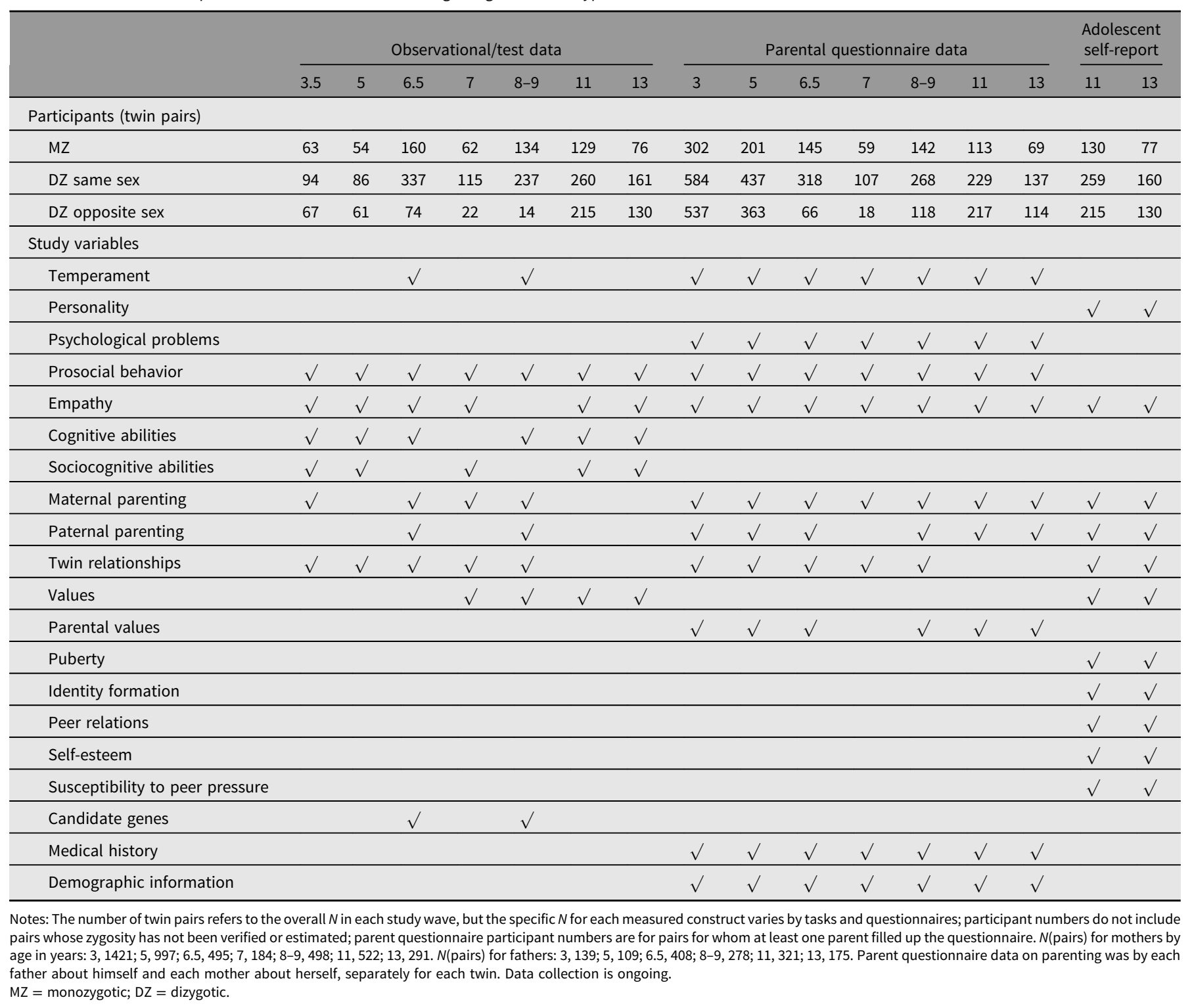

assigned by parental questionnaires describing twins' physical similarity (54.7\%; Goldsmith, 1991). In other cases, twins were assigned as dizygotic (DZ) when they were conceived via in-vitro fertilization $(0.7 \%)$, and one family's zygosity was assigned as DZ using estimates of physical similarity from videos.

Overall, the sample includes $10.92 \%$ monozygotic (MZ) male twins, 9.72\% MZ female twins, 20.4\% DZ male twins, $19.67 \%$ DZ female twins, $35.7 \%$ opposite-sex twins and 3.6\% with undetermined zygosity. Avinun and Knafo (2013) suggested that the relatively high proportion of DZ twins reflects the relatively high number of Israeli families using assisted reproductive technologies. Table 1 presents sample sizes by zygosity for questionnaire and observational/test data at each age.

\section{Measures of Children's Development}

Measures include core variables of positive aspects of social development and specifically prosocial behavior and empathy. These variables have been collected at each time point using both questionnaire and observational or test methods (e.g. Knafo et al.,
2011; Knafo-Noam et al., 2015; Schapira et al., 2019). Starting at age 7 years, human values have been added as a core variable (Uzefovsky et al., 2016).

In addition to these core variables, we assessed children's temperament (Hasenfratz et al., 2015), their developmental delays and cognitive abilities (e.g. Kavé et al., 2013), and psychological problems (Knafo et al., 2009). These variables were assessed with lab tests, observations, or established questionnaires (e.g. Buss \& Plomin, 1984; Goodman, 1997; Kavé, 2006). Starting in early adolescence (age 11), information on relevant variables such as pubertal status (Petersen et al., 1988), personality traits (Big Five inventory; John et al., 1991), wellbeing (Life Satisfaction scale; Huebner, 1991) and identity formation (DIDS; Luyckx et al., 2008) have been added (Table 1).

\section{Measures of Children's Environment}

Life events such as hospitalization and family structure changes are monitored at each assessment. Parenting, assessed by observations, parent reports and adolescent reports, has also been a focus of LIST 
(Knafo et al., 2011; Pener-Tessler et al., 2013). From twins' pregnancy and birth history (Fortuna et al., 2011) to aspects of the school environment in adolescence, variables in LIST are adapted to children's developmental period. As adolescence starts (age 11), measures of the peer group and emerging romantic relationships have been added.

\section{Genetic Assessment}

To study $r \mathrm{GE}$, we focus on three neurobiological systems that were previously found to be related to social behavior: the dopaminergic, the serotonergic and the oxytonergic/vasopressinergic systems (Donaldson \& Young, 2008; Girault \& Greengard, 2004; Kuepper et al., 2010). Special interest is given to several genes commonly indicated in research for differential susceptibility to the environment, such as DRD2, DRD4, COMT, brain-derived neurotrophic factor (BDNF), 5-HTTPLR and AVPR1A (Avinun \& Knafo-Noam, 2017; Knafo et al., 2011).

\section{Recent Achievements in LIST}

The recent phases of LIST have focused on the longitudinal aspects of social development and have enabled us to examine stability and change throughout development in various prosocial and temperamental characteristics. Our two main goals were to further understand morally relevant development and to study $r \mathrm{GE}$ and gene-environment interactions. Intertwin relationships have also been of interest.

\section{Morally Relevant Development}

We focus on emotional, behavioral and cognitive aspects of morally relevant development, such as empathy, prosocial behavior and values. Although empathy, defined as the ability to recognize the emotions of others and to share those emotions (Uzefovsky \& Knafo-Noam, 2017), can be seen as serving a meaningful evolutionary function (Decety et al., 2016; De Waal, 2012), it also shows substantial individual differences (Knafo et al., 2009). Work from LIST has demonstrated genetic contributions to observed empathy in early childhood (Knafo et al., 2009), although cognitive aspects of empathy such as understanding emotions tend to show lower heritability and higher shared environmental influences in middle childhood (Knafo \& Uzefovsky, 2013; Schapira et al., 2019). Further work has showed gene-environment interactions, in which variation in the exon III repeat region of the $D R D 4$ gene interacted with children's gender and with the parenting they received in affecting different aspects of children's observed empathy (Ben-Israel et al., 2015; Knafo \& Uzefovsky, 2013).

Prosocial behavior, a behavior that is aimed at benefiting others (Eisenberg et al., 2015), can be manifested in different forms such as sharing, social concern, helping and comforting. These behaviors can be either self-initiated or compliant, following a request. At age 3.5 years, we found that experimentally assessed comforting behavior correlated with helping and sharing behaviors, while sharing and helping did not correlate with each other (KnafoNoam et al., 2018). As children grew older we could study a wider variety of prosocial behaviors. At age 7 years, using parent reports, we identified five prosociality facets (sharing, social concern, kindness, helping and empathetic concern), which were positively intercorrelated ( $r>.39$; Knafo-Noam et al., 2015). This finding may point to the existence of a single prosociality trait, which perhaps crystallizes with age.
Values, which are abstract goals that guide behavior and are used as compass to determine right from wrong (Schwartz, 1992), may be seen as providing the motivational stratum of morality (Sverdlik et al., 2012). Values were traditionally considered as emerging in late adolescence, and so the majority of studies on values focus on adults. However, we found evidence that values actually develop earlier than previously thought and can be studied in children of 7 years old (Uzefovsky et al., 2016) and even younger (Abramson et al., 2018). We used the Picture-Based Value Survey for children (Döring et al., 2010), which is based on Schwartz's comprehensive and widely used account of value priorities and structure (Boehnke, 2001; Verplanken \& Holland, 2002), and found the same basic patterns of relations between value priorities and social dimensions - gender, religiosity and socioeconomic status - that have been found in adult studies (Uzefovsky et al., 2016). Although most of our work on the genetic and environmental contribution to values is ongoing, this initial report from LIST was the first to demonstrate genetic contributions to most values in young children (Uzefovsky et al., 2016). As children enter adolescence, the way they explore and commit to their future identity helps shape the development of their values (Knafo \& Schwartz, 2004). Thus, our report from age 11 years showed that individual differences in identity formation patterns are partly heritable (Markovitch et al., 2017). This suggests that value development through adolescence is likely affected by genetic factors as well.

\section{Gene-Environment Correlations}

A major goal of LIST has been to understand $r$ GE and specifically evocative $r \mathrm{GE}$, in which an individual's genetically influenced phenotype affects the reaction of his or her social environment. One such environment, peer relationships, is crucial for social development (Blakemore \& Mills, 2014). Our results show that peer problems, seen as the reaction of the peer environment to the developing child, are associated with the child's temperamental dimensions of negative emotionality and sociability at age 3 years (Benish-Weisman et al., 2010). Using longitudinal data from ages 3,5 and 6.5 years, our results indicate that peer problems (assessed by both mothers and fathers) are longitudinally associated with mother-rated negative emotionality and low sociability, over and above moderate stability of all variables (Hasenfratz et al., 2015). Heritability partly explained these associations, thus indicating the existence of evocative $r \mathrm{GE}$. This finding implies that children's genetically influenced tendency to play alone and experience intensive negative emotions is putting them at a higher risk of rejection by their peers (Hasenfratz et al., 2015).

LIST also focuses on how children's behavior influences the parenting they receive. At age 3.5, we found evidence of an evocative $r$ GE in which boys' 5-HTTLPR genotype was associated with mothers' observed positive parenting (Pener-Tessler et al., 2013). In addition, the results indicated that boys' mother-reported selfcontrol mediated the effect of boys' 5-HTTLPR genotype on mothers' positivity, such that boys' 5-HTTLPR genotype predicted their levels of self-control, which in turn predicted the levels of positive parenting they received (Pener-Tessler et al., 2013).

Parenting has also been linked to parents' own genes (Avinun et al., 2012; Pener-Tessler et al., 2013), implicating passive $r$ GE in observed associations between parenting and child behavior (Knafo \& Jaffee, 2013; Narusyte et al., 2008). Finally, to add to the complexity of the parenting-genes-child behavior network, two reports from LIST found that fathers' (but not mothers') parenting was predicted by an interaction between the val-met 
polymorphism in the BDNF gene and children's prosocial or aggressive behavior. The importance of children's behavior was exemplified by within-family twin comparisons such that Met carrier fathers differentiated more strongly between their children based on the child's behaviors (Avinun \& Knafo-Noam, 2017; Avinun et al., 2018).

\section{Twin Relationships}

Despite the importance of twins to each other, research on twins has largely neglected this relationship. In the parent-report twin relationship questionnaire, we identified five relationship factors, namely, conflict, closeness, dependence, dominance and rivalry, which related to twins' self-reported relationship and observed prosocial behavior toward each other (Segal \& Knafo-Noam, 2019). The first report from LIST on this topic found that 3-year-old MZ twins were perceived as closer and more co-twin dependent than $\mathrm{DZ}$ twins who in turn were closer and more co-dependent than a matched sample of nontwin siblings (Fortuna et al., 2010). However, using an experimental measure of intertwin prosocial behavior at the age of 6.5 years, we did not find a difference between $\mathrm{MZ}$ and $\mathrm{DZ}$ twins in their prosocial behavior toward each other (Yirmiya et al., 2018), and the two kinds of twins were similarly positively correlated with each other, suggesting that this behavior is driven by reciprocity (i.e. the likelihood of being prosocial, depending on the past and future mutual interactions), rather than relative genetic similarity between the twins. The difference between these findings may be explained by differences in the examined constructs, children's age, or research method, and stresses the need for additional research on this important topic.

\section{Summary and Future Directions}

LIST has provided ample evidence for the involvement of genetic influences and to a lesser extent also shared environmental influences in children's development (Fortuna et al., 2014; Kavé et al., 2013; Knafo et al., 2011). It has also provided evidence for the role of $r \mathrm{GE}$ and gene-environment interactions (e.g. BenishWeisman et al., 2015; Fortuna et al., 2011).

Current research plans for LIST focus on adolescence until the age of 17 years and hopefully beyond. Adolescent research will investigate the genetic and environmental contributions to values as well as the development, crystallization and genetic origins of values-personality associations that are evident in adulthood (Fischer \& Boer, 2015). As adolescents grow up, in addition to our continued focus on parenting, more emphasis will be given to other social environments that increase in their importance during this developmental period, such as the school and neighborhood. At the same time, LIST will seek to include polygenic information to further our understanding of the genetic factors involved in social behavior. After studying early, middle and late childhood, the transition to adolescence and then emerging adulthood will be at the heart of future research in LIST.

The email address of LIST is mehkar.teomim@gmail.com. Our website address is http://soc-lab.com.

Acknowledgements. We thank Gali Naor, Moran Shalmon, Tamar Gutbir, Naama Gilat, Roni Pener-Tessler, Hen Nave-Arbel, Chen Regev-Limoni, Noam Markovitch and Dana Katsoty for coordinating the data collection at different stages of LIST. LIST has been supported by the Israel Science Foundation (grants No. 31/06, 1670/13, 1333/18). Further support was obtained by a grant from The Science of Generosity Initiative, University of Notre Dame funded by the John Templeton Foundation and by starting grant no. 240994 from the European Research Council (ERC) both to Ariel Knafo. We also thank the Bloomfield Science Museum in Jerusalem for their support of the twin study participant meeting. Most importantly, we thank the parents and children in our study for their continued support and participation.

\section{References}

Abramson, L., Daniel, E., \& Knafo-Noam, A. (2018). The role of personal values in children's costly sharing and non-costly giving. Journal of Experimental Child Psychology, 165, 117-134.

Avinun, R, Davidov, M., Mankuta, D., \& Knafo-Noam, A. (2018). Predicting the use of corporal punishment: Child aggression, parent religiosity, and the BDNF gene. Aggressive Behavior, 44, 165-175.

Avinun, R., Ebstein, R. P., \& Knafo, A. (2012). Human maternal behavior is associated with arginine vasopressin receptor 1A (AVPR1A) gene. Biology Letters, 8, 894-896.

Avinun, R., \& Knafo, A. (2013). The Longitudinal Israeli Study of Twins (LIST) - An integrative view of social development. Twin Research and Human Genetics, 16, 197-201.

Avinun, R., \& Knafo-Noam, A. (2017). Parental brain-derived neurotrophic factor genotype, child prosociality, and their interaction as predictors of parents' warmth. Brain and Behavior, 7, e00685.

Benish-Weisman, M., Kerem, E., Knafo-Noam, A., \& Belsky, J. (2015). The moderating role of genetics: The effect of length of hospitalization on children's internalizing and externalizing behaviors. Frontiers in Psychiatry, 6, 109.

Benish-Weisman, M., Steinberg, T., \& Knafo, A. (2010). Genetic and environmental links between children's temperament and their problems with peers. Israel Journal of Psychiatry, 47, 144-151.

Ben-Israel, S., Uzefovsky, F., Ebstein, R. P., \& Knafo-Noam, A. (2015). Dopamine D4 receptor polymorphism and sex interact to predict children's affective knowledge. Frontiers in Psychology, 6, 846.

Blakemore, S. J., \& Mills, K. L. (2014). Is adolescence a sensitive period for sociocultural processing? Annual Review of Psychology, 65, 187-207.

Boehnke, K. (2001). Parent-offspring value transmission in a societal context: Suggestions for a utopian research design - With empirical underpinnings. Journal of Cross-Cultural Psychology, 32, 241-255.

Burt, S. A. (2009). Rethinking environmental contributions to child and adolescent psychopathology: A meta-analysis of shared environmental influences. Psychological Bulletin, 135, 608.

Buss, A. H., \& Plomin, R. (1984). Temperament: Early developing personality traits. Hillsdale, NJ: Lawrence Erlbaum Associates.

Davidov, M., Knafo-Noam, A., Serbin, L. A., \& Moss, E. (2015). The influential child: How children affect their environment and influence their own risk and resilience. Development and Psychopathology, 27, 947-951.

Decety, J., Bartal, I. B. A., Uzefovsky, F., \& Knafo-Noam, A. (2016). Empathy as a driver of prosocial behaviour: Highly conserved neurobehavioural mechanisms across species. Philosophical Transactions of the Royal Society B: Biological Sciences, 371, 20150077.

De Waal, F. B. (2012). The antiquity of empathy. Science, 336, 874-876.

Donaldson, Z. R., \& Young, L. J. (2008). Oxytocin, vasopressin, and the neurogenetics of sociality. Science, 322, 900-904.

Döring, A. K., Blauensteiner, A., Aryus, K., Drögekamp, L., \& Bilsky, W. (2010). Assessing values at an early age: The picture-based value survey for children (PBVS-C). Journal of Personality Assessment, 92, 439-448.

Eisenberg, N., Spinrad, T. L., \& KnafoNoam, A. (2015). Prosocial development. In M. E. Lamb \& R. N. Lerner (Eds.), Handbook of child psychology and developmental science: Socioemotional processes (pp. 1-47). Hokoben, NJ: Wiley.

Fischer, R., \& Boer, D. (2015). Motivational basis of personality traits: A meta-analysis of value personality correlations. Journal of Personality, 83, 491-510.

Fortuna, K., Baor, L., Israel, S., Abadi, A., \& Knafo, A. (2014). Attachment to inanimate objects and early childcare: A twin study. Frontiers in Psychology, $5,486$. 
Fortuna, K., Goldner, I., \& Knafo, A. (2010). Twin relationships: A comparison across monozygotic twins, dizygotic twins and nontwin siblings in early childhood. Family Science, 1, 205-211.

Fortuna, K., van Ijzendoorn, M. H., Mankuta, D., Kaitz, M., Avinun, R., Ebstein, R. P., \& Knafo, A. (2011). Differential genetic susceptibility to child risk at birth in predicting observed maternal behavior. PLoS One, 6, e19765.

Girault, J., \& Greengard, P. (2004). The neurobiology of dopamine signaling. Archives of Neurology, 61, 641.

Goldsmith, H. (1991). A zygosity questionnaire for young twins: A research note. Behavior Genetics, 21, 257-269.

Goodman, R. (1997). The strengths and difficulties questionnaire: A research note. Journal of Child Psychology and Psychiatry, 38, 581-586.

Hasenfratz, L., Benish-Weisman, M., Steinberg, T., \& Knafo-Noam, A. (2015). Temperament and peer problems from early to middle childhood: Gene-environment correlations with negative emotionality and sociability. Development and Psychopathology, 27, 1089-1109.

Huebner, E. S. (1991). Further validation of the Students' Life Satisfaction Scale: The independence of satisfaction and affect ratings. Journal of Psychoeducational Assessment, 9, 363-368.

Israel, S., Hasenfratz, L., \& Knafo-Noam, A. (2015). The genetics of morality and prosociality. Current Opinion in Psychology, 6, 55-59.

John, O. P., Donahue, E. M., \& Kentle, R. L. (1991). The big five inventory Version $4 a$ and 54. Berkeley, CA: Berkeley Institute of Personality and Social Research, University of California.

Kavé, G. (2006). The development of naming and word fluency: Evidence from Hebrew-speaking children between ages 8 and 17. Developmental Neuropsychology, 29, 493-508.

Kavé, G., Shalmon, M., \& Knafo, A. (2013). Environmental contributions to preschoolers' semantic fluency. Developmental Science, 16, 124-135.

Knafo, A. (2006). The Longitudinal Israeli Study of Twins (LIST): Children's social development as influenced by genetics, abilities, and socialization. Twin Research and Human Genetics, 9, 791-798.

Knafo, A., Israel, S., \& Ebstein, R. P. (2011). Heritability of children's prosocial behavior and differential susceptibility to parenting by variation in the dopamine receptor D4 gene. Development and Psychopathology, 23(1), 53-67.

Knafo, A., \& Jaffee, S. R. (2013). Gene-environment correlation in developmental psychopathology. Development and Psychopathology, 25, 1-6.

Knafo, A., \& Schwartz, S. H. (2004). Identity status and parent-child value congruence in adolescence. British Journal of Developmental Psychology, 22, 439-458.

Knafo, A., \& Uzefovsky, F. (2013). Variation in empathy: The interplay of genetic and environmental factors. In M. Legerstee, D. W. Haley, \& M. H. Bornstein (Eds.), The infant mind: Origins of the social brain (pp. 97-122). New York, NY: Guilford Press.

Knafo, A., Zahn-Waxler, C., Davidov, M., Van Hulle, C., Robinson, J. L., \& Rhee, S. H. (2009). Empathy in early childhood: Genetic, environmental, and affective contributions. Annals of the New York Academy of Sciences, 1167, 103-114.

Knafo-Noam, A., Uzefovsky, F., Israel, S., Davidov, M., \& Zahn-Waxler C. (2015). The prosocial personality and its facets: Genetic and environmental architecture of mother-reported behavior of 7-year-old twins. Frontiers in Psychology, 6, 112.

Knafo-Noam, A., Vertsberger, D., \& Israel, S., (2018). Genetic and environmental contributions to children's prosocial behavior: Brief review and new evidence from a reanalysis of experimental twin data. Current Opinion in Psychology, 20, 60-65.
Kuepper, Y., Alexander, N., Osinsky, R., Mueller, E., Schmitz, A., Netter, P., \& Hennig, J. (2010). Aggression - Interactions of serotonin and testosterone in healthy men and women. Behavioral Brain Research, 206, 93-100.

Luyckx, K., Schwartz, S. J., Berzonsky, M. D., Soenens, B., Vansteenkiste, M., Smits, I., \& Goossens, L. (2008). Capturing ruminative exploration: Extending the four-dimensional model of identity formation in late adolescence. Journal of Research in Personality, 42, 58-82.

Markovitch, N., Luyckx, K., Klimstra, T., Abramson, L., \& Knafo-Noam, A. (2017). Identity exploration and commitment in early adolescence: Genetic and environmental contributions. Developmental Psychology, 53, 2092-2102.

Narusyte, J., Neiderhiser, J. M., D’onofrio, B. M., Reiss, D., Spotts, E. L., Ganiban, J., \& Lichtenstein, P. (2008). Testing different types of genotype-environment correlation: An extended children-of-twins model. Developmental Psychology, 44, 1591.

Pener-Tessler, R., Avinun, R., Uzefovsky, F., Edelman, S., Ebstein, R. P., \& Knafo, A. (2013). Boys' serotonin transporter (SLC6A4) 5-HTTLPR genotype affects maternal behavior through boys' self-control: A case of evocative gene-environment correlation. Development and Psychopathology, 25, 151-162.

Petersen, A. C., Crockett, L., Richards, M., \& Boxer, A. (1988). A self-report measure of pubertal status: Reliability, validity, and initial norms. Journal of Youth and Adolescence, 17, 117-133.

Plomin, R., DeFries, J. C., \& Loehlin, J. C. (1977). Genotype-environment interaction and correlation in the analysis of human behavior. Psychological Bulletin, 84, 309-322.

Rutter, M., Moffitt, T. E., \& Caspi, A. (2006). Gene-environment interplay and psychopathology: Multiple varieties but real effects. Journal of Child Psychology and Psychiatry, 47, 226-261.

Schapira, R., Elfenbein, H. A., Amichay-Setter, M., Zahn-Waxler, C., \& Knafo-Noam, A. (2019). Shared environment effects on children's emotion recognition. Frontiers in Psychiatry, 10, 215.

Schwartz, S. H. (1992). Universals in the content and structure of values: Theoretical advances and empirical tests in 20 countries. Advances in Experimental Social Psychology, 25, 1-65.

Segal, H., \& Knafo-Noam, A. (2019). The twin relationship questionnaire: Testing a five-factor model from early to middle childhood. European Journal of Psychological Assessment, 1, 1-13.

Sverdlik, N., Roccas, S., \& Sagiv, L. (2012). Morality across cultures: A value perspective. In M. Mikulincer \& P. R. Shaver (Eds.), The social psychology of morality: Exploring the causes of good and evil (pp. 219-236). Washington, DC: American Psychological Association.

Uzefovsky, F., Döring, A. K., \& Knafo-Noam, A. (2016). Values in middle childhood: Social and genetic contributions. Social Development, 25, 482502.

Uzefovsky, F., \& Knafo-Noam, A. (2017). Empathy development throughout the lifespan. In J. Sommerville \& J. Decety (Eds.), Social cognition: Frontiers in developmental science series (pp. 71-97). New York, NY: Psychology Press, Taylor and Francis Group.

Verplanken, B., \& Holland, R. W. (2002). Motivated decision making: Effects of activation and self-centrality of values on choices and behavior. Journal of Personality and Social Psychology, 82, 434-447.

Yirmiya, K., Segal, N. L., Bloch, G., \& Knafo-Noam, A. (2018). Prosocial and self-interested intra-twin pair behavior in monozygotic and dizygotic twins in the early to middle childhood transition. Developmental Science, 21, e12665. 